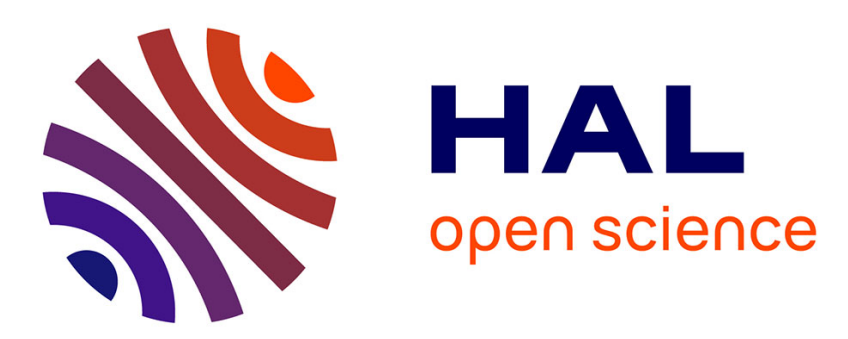

\title{
Boosting electrical conductivity in a gel-derived material by nanostructuring with trace carbon nanotubes
} David Canevet, Ángel del Pino, David-B. Amabilino, Marc Sallé

\section{To cite this version:}

David Canevet, Ángel del Pino, David-B. Amabilino, Marc Sallé. Boosting electrical conductivity in a gel-derived material by nanostructuring with trace carbon nanotubes. Nanoscale, 2011, 3 (7), pp.2898-2902. 10.1039/C1NR10235D . hal-03344618

\section{HAL Id: hal-03344618 \\ https://univ-angers.hal.science/hal-03344618}

Submitted on 15 Sep 2021

HAL is a multi-disciplinary open access archive for the deposit and dissemination of scientific research documents, whether they are published or not. The documents may come from teaching and research institutions in France or abroad, or from public or private research centers.
L'archive ouverte pluridisciplinaire HAL, est destinée au dépôt et à la diffusion de documents scientifiques de niveau recherche, publiés ou non, émanant des établissements d'enseignement et de recherche français ou étrangers, des laboratoires publics ou privés. 


\title{
Boosting electrical conductivity in a gel-derived material by nanostructuring with trace carbon nanotubes $\dagger$
}

\author{
David Canevet, ${ }^{a}$ Angel Pérez del Pino, ${ }^{b}$ David B. Amabilino*b and Marc Sallé $* a$ \\ Received 3rd March 2011, Accepted 20th April 2011 \\ DOI: $10.1039 / \mathrm{c} 1 \mathrm{nr} 10235 \mathrm{~d}$
}

\begin{abstract}
An organogelator with two distinct $\pi$-functional units is able to incorporate carbon nanotubes into its mesh of fibres in the gel state. The morphology of the material derived from this nanocomposite after evaporation of the solvent is a complex mesh of fibres which is clearly different from the pure gelator. This feature indicates a role of the nanotubes in assisting the formation of a fibre structure in the gel thanks to their interaction with the pyrene units in the organogelator. The nanocomposite conducts electricity once the p-type gelator is doped with iodine vapour. The change in morphology caused by the carbon material increases the conductivity of the material compared with the purely organic conducting system. It is remarkable that this improvement in the physical property is caused by an extremely small proportion of the carbon material (only present at a ratio of $0.1 \% \mathrm{w} / \mathrm{w}$ ). The practically unique properties of TTF unit allow measurements with both doped and undoped materials with conducting atomic force microscopy which have demonstrated that the carbon nanotubes are not directly responsible for the increased conductivity.
\end{abstract}

\section{Introduction}

As a multidisciplinary field at the frontier between physics, materials science and chemistry, molecular electronics ${ }^{1-3}$ aims at adapting macroscopic technologies at a nanometric scale, e.g. by physically interconnecting functional molecules through nanowires. These cables should ensure communication between the different subunits and need therefore to ensure good charge transport efficiency for instance. Towards this aim, different approaches have been developed which are based on two major concepts, namely the preparation of fully conjugated single molecule organic nanowires ${ }^{4-7}$ or the supramolecular assembly of electroactive units that self-assemble. ${ }^{8-12}$ The latter possibility is particularly promising since this strategy requires less synthetic efforts, and the chemical structure of the buildingblocks can be modulated with a high flexibility. In this context, organogelators have proven to be interesting precursors for such self-assembly processes since the evaporation of the gelated solvent affords a network of intertwined nanofibers. ${ }^{13-16}$ Considering its defect tolerance, such a morphology is especially relevant when aiming at preparing nanocircuits. ${ }^{17}$ On the

${ }^{a}$ Laboratoire MOLTECH-Anjou, UMR CNRS 6200, Université d'Angers, 2 Bd Lavoisier, 49045 Angers Cedex, France. E-mail: marc.salle@, univ-angers. $f r$

${ }^{b}$ Institut de Ciència de Materials de Barcelona (ICMAB-CSIC), Campus Universitari de Bellaterra, 08193 Cerdanyola del Vallès, Catalonia, Spain. E-mail:amabilino@icmab.es

$\dagger$ Electronic supplementary information (ESI) available: Details concerning the preparation of $\mathbf{1}-$ SWCNTs composite. See DOI: $10.1039 / \mathrm{c} 1 \mathrm{nr} 10235 \mathrm{~d}$ other hand, tetrathiafulvalene (TTF) and its derivatives are established $\pi$-donating systems ${ }^{18,19}$ whose conducting properties have been explored extensively in single crystals where they are present in the neutral and oxidized radical-cation state, which led to the first superconducting organic materials. ${ }^{20}$ Since 2005, TTF-based organogels have received an increasing attention $^{12}$ and in some cases, produced conducting nanofibers through oxidation of the corresponding xerogels. ${ }^{21-28}$ Single walled carbon nanotubes (SWCNTs), for their part, are peculiarly fascinating electron accepting materials with remarkable mechanical and conducting properties. ${ }^{29-31}$ However, because of their very low solubility, their use needs specific methodologies. In particular, their non-covalent functionalization with solubilizing/dispersing agents has been achieved through templating with large polyaromatic platforms. ${ }^{32}$ The efficiency of this method has been also applied to the case of organogels containing SWCNTs. ${ }^{33-36}$ One recent case showed the incorporation of SWCNTs in an oligophenylenevinylene-based gel, giving rise to a dried gel whose electrical conducting properties were promoted by the SWCNTs partner. However, the incorporation of nanotubes into intrinsically conducting supramolecular soft material has to the best of our knowledge not been explored.

We describe in this paper the first TTF-based xerogel able to incorporate CNTs, thanks to the presence of pyrene units in the organogelator, and show that the nanocomposite maintains its conducting character, and that the nanotubes promote a change in morphology which increases the conductivity of the materials compared with the pure conducting organic system. 


\section{Results and discussion}

Compound $\mathbf{1}$ was designed with a double objective: (i) being able to promote gelation; (ii) allowing a non-covalent attachment with SWCNTs. For this reason, we synthesized a TTF derivative including different functions likely to favor intermolecular interactions (Scheme 1). Long alkyl chains and amide functions are grafted onto the periphery of the TTF core in order to promote intermolecular van der Waals and hydrogen bonding interactions, respectively. As regularly observed in the crystalline state, $\mathrm{S} \cdots \mathrm{S}$ contacts inherent to the tetraalkylsulfanyl-TTF framework ${ }^{20}$ can also contribute to the self-assembling process. The pyrene units have a double role since they may help gelation through $\pi-\pi$ interactions $\mathrm{s}^{37}$ and do allow the anchoring of organogelating 1 on the SWCNTs. Synthetic details as well as gelation properties of $\mathbf{1}$ have already been reported in a recent article. $^{38}$

Gelation tests were performed in four solvents, namely tetrahydrofuran (THF), chlorobenzene (CB), o-dichlorobenzene (ODCB) and chloroform at the corresponding critical gelation concentration (CGC). Various samples were prepared with increasing amounts of SWCNTs (from $0.01 \%$ to $1 \%$ in weight with respect to the gelator 1 - see Experimental section and ESI $\dagger$ ) resulting in the following observations: (i) as previously reported with other systems,${ }^{34}$ the gels were reinforced in the presence of nanotubes (no solvent was released even after a few days), (ii) heterogeneous gels were systematically obtained when the nanotubes ratio was over $0.1 \%$ by weight with respect to the gelator 1, and (iii) the most homogeneous samples were obtained from ODCB (Fig. 1). These observations show that compound 1 does display an ability to disperse SWCNTs, even though this capacity is relatively weak compared with other previous examples. ${ }^{34}$

As a consequence, the forthcoming studies were carried out on the nanocomposite xerogels obtained from ODCB. The fact that inhomogeneous materials were obtained above $0.1 \%$ is an indication that the SWCNTs have a great propensity to coagulate before the gelation takes place. In some instances, homogeneous solutions were apparently formed in the hot solvent, but upon cooling the carbon material precipitated before the organogel could form. As observed with xerogels prepared from 1 alone, the ones incorporating SWCNTs present the typical $\mathrm{NH}$ and $\mathrm{CO}$ infrared absorption bands for materials self-assembled by hydrogen bonding. This feature indicates that the primary structure of the supramolecular fibers is unaffected by the presence of the SWCNTs. NMR experiments were also performed in

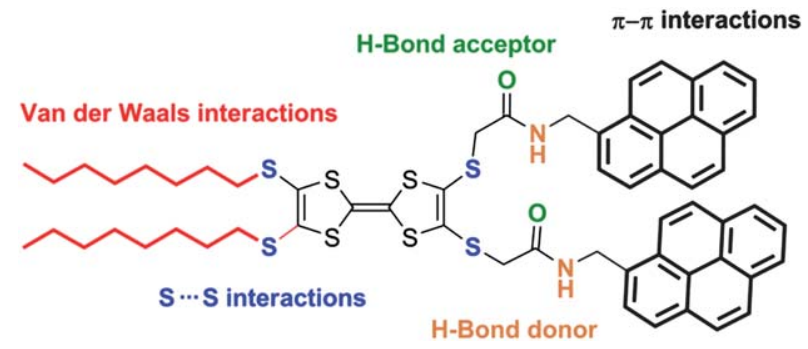

Scheme 1 Multifunctional TTF derivative 1 pointing out multiple interaction sites involved along the gelation process.

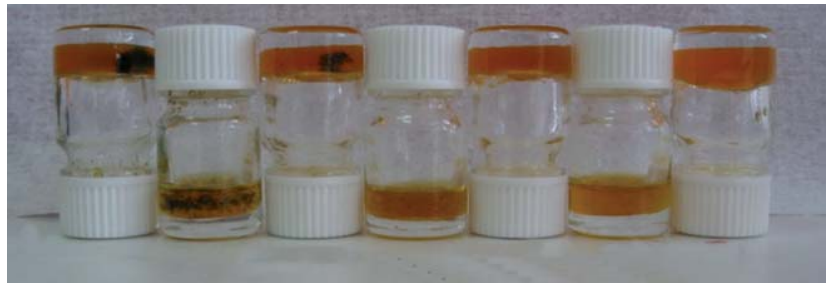

Fig. 1 Organogels 1-SWCNTs obtained from 1 and containing decreasing amounts of SWNTs $(1,0.5,0.2,0.1,0.05,0.02$, and $0.01 \% \mathrm{w} / \mathrm{w}$, respectively from left to right) (from ODCB).

the gel state to have an insight on the structuring role of SWCNTs (Fig. S2 and S3 $†$ ). The presence of SWCNTs has no effect on the chemical shift of the NH signal, which is consistent with the IR absorption study. However, the aromatic region of the spectrum was significantly modified with variations of chemical shifts up to $0.07 \mathrm{ppm}$ either upfield or downfield. This cannot solely be ascribed to the interactions between compound 1 and nanotubes given the tiny amount of the latter. This result confirms both the influence of the nanotubes on the aggregation process of gelator 1 and their structuring effect on the whole material.

Transmission electron microscopy (TEM) images show that the morphology of the nanocomposite is changed significantly by the presence of the SWCNTs when compared with pure $\mathbf{1}$. Indeed, from a random network of essentially single nanofibers which form a complex porous mesh in the case of the xerogel prepared from 1 alone, the material was converted to bundles of nanofibers whose diameter reaches few hundreds of nanometres in the case of 1-SWNTs (Fig. 2). In these aggregates, wider tapelike fibers are organized in a much more parallel fashion in bundles, which could favor conductivity in that such alignment limits the number of inter-fibers crossing points for a particular conducting pathway. It was not possible to identify the nanotubes in the images made of the nanocomposite, since the contrast is very similar throughout the sample, which was not treated with any contrast agent. This observation also supports the idea that the SWCNTs are "molecularly dispersed" in the gelator material, which presumably surrounds the carbon material completely. To investigate the conducting properties of the new SWCNT-containing composite xerogels, iodine oxidation was performed in order to partially generate radical-cation TTF units, producing the new xerogel $\mathbf{1}^{-1} \mathbf{1}^{+}-\mathrm{I}_{3}{ }^{-}-\mathrm{SWCNT}$.

The doping time of the neutral gel in iodine vapor was chosen to be 5 minutes, because it was shown by infrared absorption, ${ }^{39,40}$ AFM and EPR studies, that the efficiency of the process is optimum at this period. The EPR signal and the IR spectrum (Fig. S4 $\dagger$ ) of this nanocomposite ${ }^{38}$ were the same as those of the pure gel, indicating that the supramolecular arrangement of the TTF moieties is not changed significantly upon incorporation of the SWCNTs in the fibers.

Conducting Atomic Force Microscopy (C-AFM) measurements were subsequently performed on the doped xerogel $1-\mathbf{1}^{+}{ }_{-}^{-}$ $\mathrm{I}_{3}{ }^{-}-\mathrm{SWCNT}$, whereby the gel was formed on a graphite surface (which was used as a contact to the sample) while a conducting AFM tip was scanned over the dried and doped sample to provide current maps. 


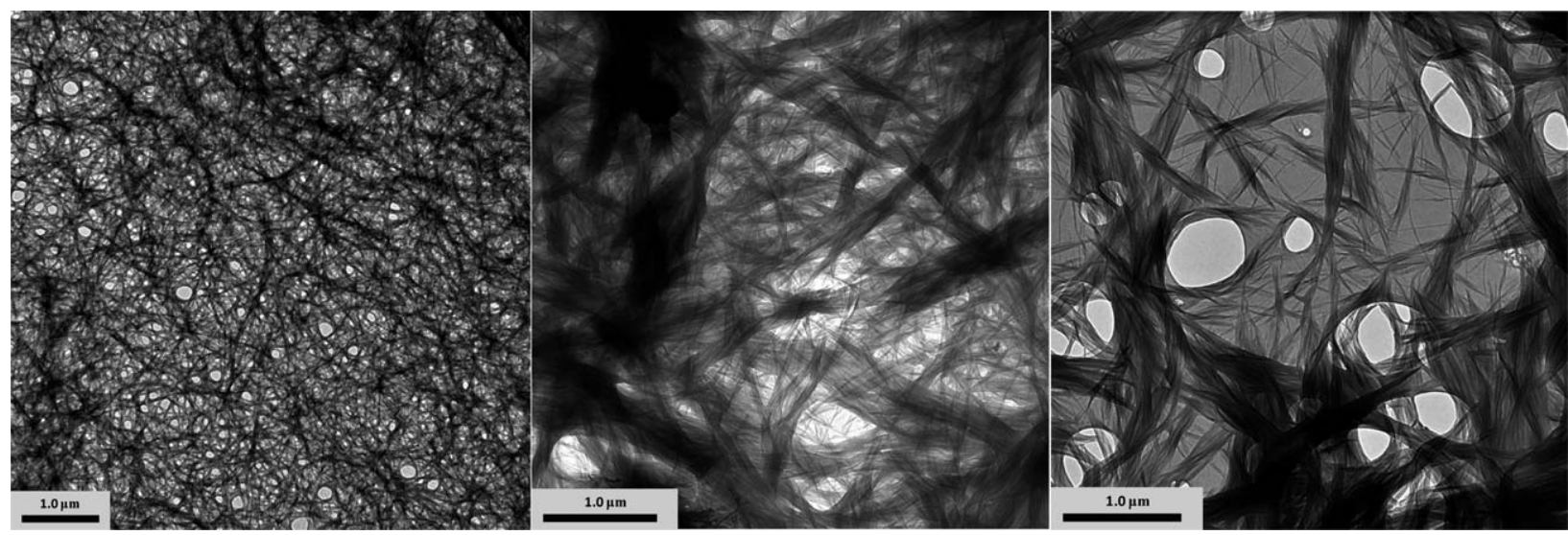

Fig. 2 TEM images of the xerogel prepared from 1 (from ODCB) without (left) and with SWNTs $0.1 \%$ w/w (middle and right).

Comparison of the C-AFM images of the doped xerogel samples with and without nanotubes (Fig. 3) shows both a change in the perceived topography and a significant increase in the conductivity when the xerogel was doped with a tiny amount of SWCNTs $(1 \mu \mathrm{g}$ of SWCNTs for $1 \mathrm{mg}$ of $\mathbf{1}(0.1 \% \mathrm{w} / \mathrm{w}))$. The sample containing SWCNTs shows areas with slightly more fibrous appearance than the pure 1 , in line with the TEM measurements. The current scale in the images also reveals the significantly greater conductivity of the nanocomposite. It is
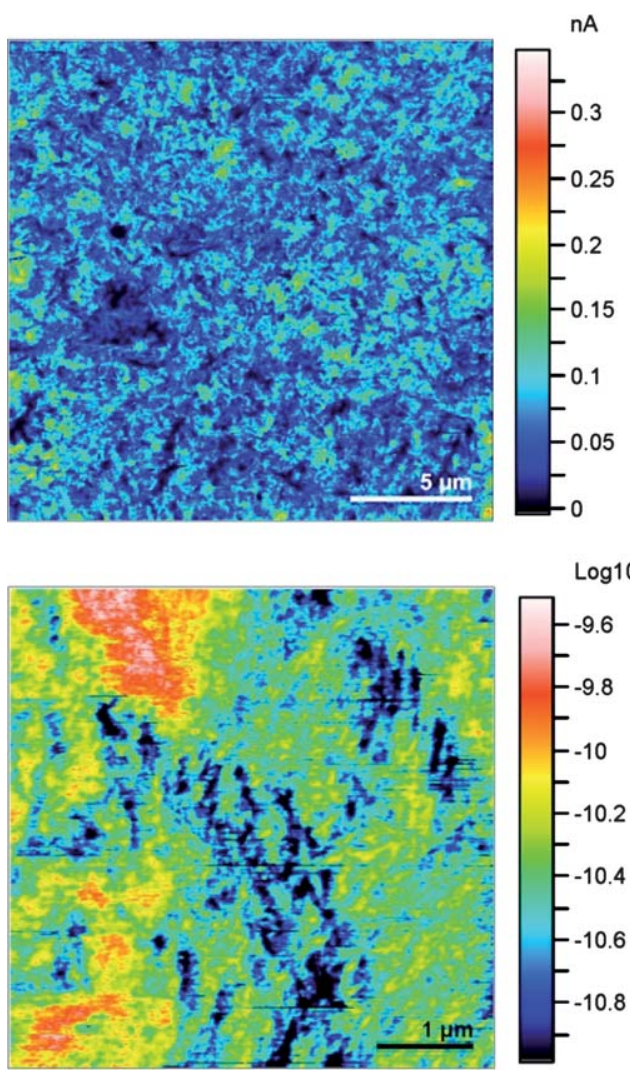

Fig. 3 C-AFM images of a xerogel 1 prepared from ODCB and doped with $\mathrm{I}_{2}$ (above) and that of the analogous xerogel doped with $\mathrm{I}_{2}$ and incorporating SWCNTs $\left(0.1 \%\right.$ w/w) $\quad\left(\mathbf{1}^{\left.-\mathbf{1}^{+}-\mathrm{I}_{3}-\mathrm{SWCNT}\right)}\right.$ (below) applying a $1 \mathrm{~V}$ voltage (note that current scales are different for an easier comparison). important to note that the resistance of the non-doped xerogel containing the SWCNTs is of the order of $\mathrm{T} \Omega$, and therefore the nanotubes do not contribute significantly to the bulk conductivity of the nanocomposite.

The structuring effect promoted by SWCNTs incorporation into the gel was confirmed by this scanning probe technique, where the fibres are far more apparent, as revealed in Fig. 4 which shows the physical topography with the current signals overlaid in colour. It should be noted that the current maxima do not coincide directly with the highest parts of the surface, and that the conducting fibres follow the contours, emphasizing the fact that the material was produced from a soft nanocomposite.

The increased conductivity in the sample containing SWCNTs appears even more clearly when comparing current histograms presented in Fig. 5. In particular, a fairly conducting sample is observed once oxidation has been carried out on the xerogel of 1 with iodine; such behaviour is coherent with the well-established conducting properties of cation-radical salts of TTF derivatives and has been observed in some recent examples of TTF-based xerogels. ${ }^{21-23,25-27}$ Currents are in this case spread from 0 to $40 \mathrm{pA}$ with a maximum at $9 \mathrm{pA}$. The situation is quite different for the same xerogel once it incorporates SWCNTs $(0.1 \% \mathrm{w} / \mathrm{w})$. In this case, remarkably, a significant magnification of currents is

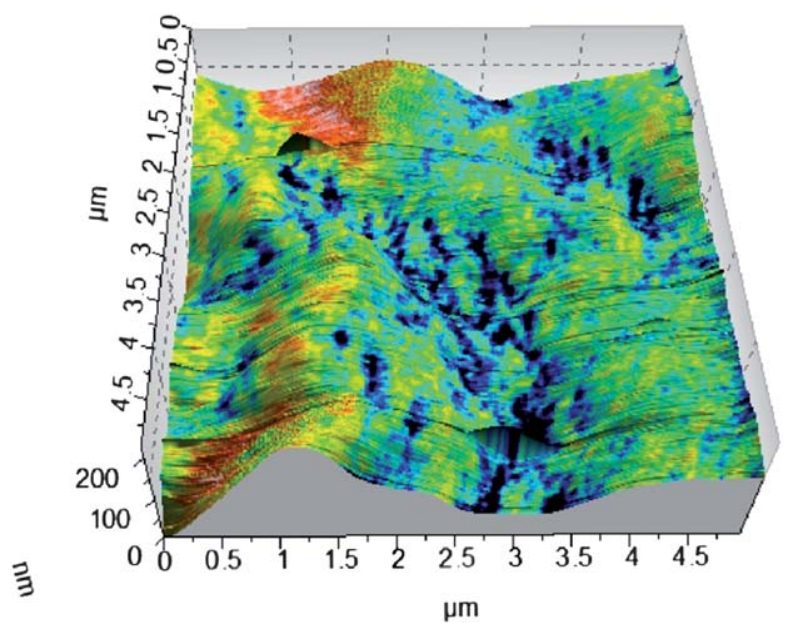

Fig. 4 C-AFM images (at a potential of $1 \mathrm{~V}$ ) of a xerogel $\mathbf{1}^{-\mathbf{1}^{+}-\mathrm{I}_{3}{ }^{-}-}$ SWCNT showing 3D topography with current overlaid in colour. 


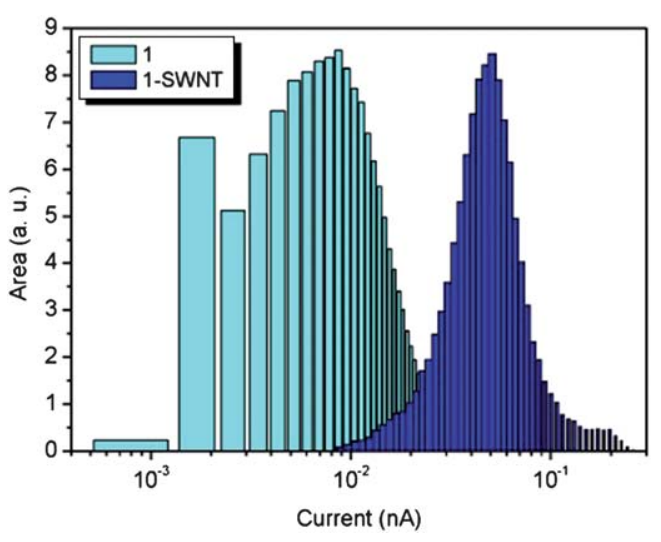

Fig. 5 Current histograms observed upon C-AFM measurements obtained with a bias of $1 \mathrm{~V}$ in the doped xerogel of $\mathbf{1}$ prepared from ODCB and in the same xerogel in the presence of SWCNTs.

observed, the latter being comprised between $10 \mathrm{pA}$ and $240 \mathrm{pA}$ with a maximum reached at $51 \mathrm{pA}$. In terms of resistances, average values are around $20-300 \mathrm{G} \Omega$ and 3-70 G $\Omega$ for the doped xerogel 1 without and with SWCNTs, respectively. In other words, the material's resistance is reduced by $c a$. 4-6 times due to the presence of nanotubes.

The C-AFM technique also allowed measurement of $I-V$ curves in different areas of the xerogels (Fig. 6) and demonstrates that the originally fully semiconducting material (without SWCNTs) was converted into a more conductive one upon incorporation of SWCNTs which is naturally an asset for a lower resistivity. It is worth noting that, in some micrometric locations, very high conductive behaviour was observed. These areas, whose resistance was about six orders of magnitude lower than the rest of the sample, showed metallic (Ohmic) nature and they could be related to zones with high alignment of fibres, where their conducting nature becomes predominant. During the C-AFM measurements a metallic tip is kept in contact with the composite, which is a p-type semiconductor, leading to the formation of a Schottky contact. In this case, the system shows a rectifying behaviour suggesting a lower value of the metal work function than the composite one (otherwise it would show an ohmic nature). In this kind of system, the bending of the energy bands in the contact-interface of the semiconducting material forms an asymmetric potential barrier which provokes a totally different carrier transport at both positive and negative applied biases.

Although the carbon nanotubes are present in tiny amounts, the metallic character observed in these areas raises an important
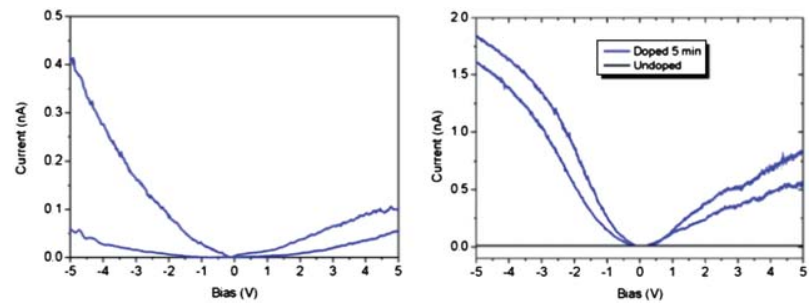

Fig. $6 I-V$ curves for the doped xerogel of 1 prepared from ODCB (above) and the doped xerogel containing $0.1 \% \mathrm{w} / \mathrm{w}$ SWCNTs (below). The modulus of the current is depicted. question regarding nanotube's role in the conducting properties of the xerogels. Indeed, these carbon nanostructures are very well-known for, among other properties, their outstanding conductivity. ${ }^{41}$ To address this issue, a last series of experiments was performed, consisting in measuring the xerogel conductivity of a noniodine-doped 1-SWCNT xerogel. In this case, neutral TTF units do not participate to the conduction process, and if any, the latter would be due to the contribution of SWCNTs alone. Currents of less than $10 \mathrm{fA}$ (the limit of the detector) were detected with these samples in the same conditions $(E \leq 1 \mathrm{~V})$, demonstrating that SWNTs do not participate to the electronic transport. These measurements confirm that nanotubes are dispersed in the materials and that they act as a structuring reagent, which changes the organization within the xerogel to afford more conductive materials. In that, their role is similar to a catalyst for charge transport since (i) they are present in very low ratios and (ii) their structuring effect allows a high increase in the conductivity even if they do not intrinsically contribute to the charge transport.

\section{Conclusions}

The tetrathiafulvalene derivative described in this paper is a promising candidate for conducting supramolecular wires, and the use of single walled carbon nanotubes as a structuring element improves the electrical conductivity of the doped xerogels that are derived from them. This improvement in the physical property is aided by a structuring of the supramolecular fibres by the carbon nanotubes, which are present in extremely small quantities $(0.1 \% \mathrm{w} / \mathrm{w})$. This low proportion of carbon nanotubes - a result of their poor solubilization by the TTF derivative - results in a quite local structuring of the material which improves the bulk conductivity appreciably, and improves the conductivity dramatically in very small areas. Thanks to the singular electrochemical properties of TTF, we have been able to perform measurements with both doped and undoped materials and have demonstrated that the carbon nanotubes are not directly responsible for the increased conductivity. It could be that the improved solubilization of the nanotubes by new gelators could give rise to multifunctional materials which take advantage of both the conducting properties of the molecular conductor and the mechanical properties of the carbon nanotubes, as well as the potential of the two components to act as hole and electron conductors, respectively, areas we will explore.

\section{Experimental section}

\section{Materials}

Purified carbon nanotubes were purchased from Carbon Solutions Inc. and used without further treatment. Their average diameter and length are $1.4 \mathrm{~nm}$ and $1 \mu \mathrm{m}$, respectively, and their structure is close to pristine nanotubes. Compound $\mathbf{1}$ was prepared according to ref. 38 .

Preparation of organogels. The organogels from 1 were prepared following this sequence: (i) the desired amount of compound 1 was suspended in the solvent in order to reach the critical gelation concentration (CGC) once dissolved; (ii) the sample was heated till complete solubilisation and (iii) the 
mixture was allowed to cool to r.t. until gelation. To prepare the 1-CNTs composites: (i) CNTs were dispersed by sonication in a solvent for 30 minutes; (ii) the desired volume was added to a heated solution of compound $\mathbf{1}$ in the same solvent; (iii) the mixture was homogenised and left until gelation. The warm solution of 1 had previously been prepared with the necessary amount of $\mathbf{1}$ and the suitable volume of solvent, so as to afford $0.5 \mathrm{~mL}$ of organogel, which concentration was equal to the CGC and which contained the desired ratio of CNTs. Further details are given in the ESI†.

\section{Doping process}

The doping process was performed by introducing the xerogel deposited on a substrate in a chamber saturated with iodine vapours for five minutes.

\section{Instrumentation}

The ESR spectra were obtained using a Bruker ELEXYS E500 X band spectrometer on a doped sample of the xerogel on a glass slide. TEM images were acquired with a Jeol JEM 2011 microscope on unstained samples. Holey carbon grids were used, where samples were deposited as a hot drop of solution and allowed to dry using a vacuum pump when necessary.

C-AFM. Conducting AFM characterization of the xerogels was performed with a 5500LS equipment from Agilent Technologies and a Resiscope module from CSI-Scientec for the electrical characterization. All the analyses were carried out in contact mode using a $\mathrm{Pt}$-Ir coated silicon probe with a force constant around $3 \mathrm{~N} \mathrm{~m}^{-1}$. Data treatments were made through MountainsMap 6.0 software from Digital Surf.

\section{Acknowledgements}

This work was in part supported by the program ANR PNANO (TTF-Based Nanomat), the Generalitat de Catalunya (2009 SGR 158), the MICINN-Spain (Project CTQ2010-16339) and the COST D31 Action (Organizing Non-Covalent Chemical Systems with Selected Functions).

\section{Notes and references}

1 M. C. Petty, M. R. Bryce and D. Bloor, Introduction to Molecular Electronics, Oxford University Press, USA, 1995.

2 R. L. Carroll and C. B. Gorman, Angew. Chem., Int. Ed., 2002, 41, 4378-4400.

3 K. S. Kwok and J. C. Ellenbogen, Mater. Today, 2002, 5, $28-37$.

4 N. Robertson and C. A. McGowan, Chem. Soc. Rev., 2003, 32, 96103.

5 D. James and J. Tour, Top. Curr. Chem., 2005, 257, 33-62.

6 M. J. Frampton and H. L. Anderson, Angew. Chem., Int. Ed., 2007, 46, 1028-1064.

7 D. M. Guldi, B. M. Illescas, C. M. Atienza, M. Wielopolski and N. Martín, Chem. Soc. Rev., 2009, 38, 1587-1597.

8 A. Ajayaghosh, S. J. George and A. P. H. J. Schenning, Top. Curr. Chem., 2005, 258, 83-118.

9 A. P. H. J. Schenning and E. W. Meijer, Chem. Commun., 2005, 32453258.

10 F. J. M. Hoeben, P. Jonkheijm, E. W. Meijer and A. P. H. J. Schenning, Chem. Rev., 2005, 105, 1491-1546.

11 C. C. Lee, C. Grenier, E. W. Meijer and A. P. H. J. Schenning, Chem. Soc. Rev., 2009, 38, 671-683.
12 For a review: (a) M. Hasegawa and M. Iyoda, Chem. Soc. Rev., 2010, 39, 2420-2427, for seminal articles: (b) M. Jørgensen, K. Bechgaard, T. Bjørnholm, P. Sommer-Larsen, L. G. Hansen and K. Schaumburg, J. Org. Chem., 1994, 59, 5877-5882; (c) C. Wang, D. Zhang and D. Zhu, J. Am. Chem. Soc., 2005, 127, 16372-16373; (d) T. Kitahara, M. Shirakawa, S. I. Kawano, U. Beginn, N. Fujita and S. Shinkai, J. Am. Chem. Soc., 2005, 127, 14980-14981; (e) T. Kitamura, S. Nakaso, N. Mizoshita, Y. Tochigi, T. Shimomura, M. Moriyama, K. Ito and T. Kato, J. Am. Chem. Soc., 2005, 127, 14769-14775, for recent examples:(f) C. Wang, Q. Chen, F. Sun, D. Zhang, G. Zhang, Y. Huang, R. Zhao and D. Zhu, J. Am. Chem. Soc., 2010, 132, 3092-3096; ( $g$ ) S. Prasanthkumar, A. Saeki, S. Seki and A. Ajayaghosh, J. Am. Chem. Soc., 2010, 132, 88668867; (h) S. Prasanthkumar, A. Gopal and A. Ajayaghosh, J. Am. Chem. Soc., 2010, 132, 13206-13207.

13 P. Terech and R. G. Weiss, Chem. Rev., 1997, 97, 3133-3159.

14 T. Ishi-I and S. Shinkai, Top. Curr. Chem., 2005, 258, 119-160.

15 A. Ajayaghosh and V. K. Praveen, Acc. Chem. Res., 2007, 40, 644-656.

16 J. W. Steed, Chem. Commun., 2011, 47, 1379-1383.

17 J. R. Heath, P. J. Kuekes, G. S. Snider and R. S. Williams, Science, 1998, 280, 1716-1721.

18 N. Martín and J. L. Segura, Angew. Chem., Int. Ed., 2001, 40, 1372-1409.

19 D. Canevet, M. Sallé, G. Zhang, D. Zhang and D. Zhu, Chem. Commun., 2009, 2245-2269.

20 P. Batail, Chem. Rev., 2004, 104, special issue on molecular conductors.

21 T. Kitamura, S. Nakaso, N. Mizoshita, Y. Tochigi, T. Shimomura, M. Moriyama, K. Ito and T. Kato, J. Am. Chem. Soc., 2005, 127, 14769-14775.

22 J. Puigmartí-Luis, V. Laukhin, Á. Pérez Del Pino, J. Vidal-Gancedo, C. Rovira, E. Laukhina and D. B. Amabilino, Angew. Chem., Int. Ed., 2007, 46, 238-241.

23 Y. Kobayashi, M. Hasegawa, H. Enozawa and M. Iyoda, Chem. Lett., 2007, 36, 720-721.

24 J. Puigmartí-Luis, Á. Pérez del Pino, E. Laukhina, J. Esquena, V. Laukhin, C. Rovira, J. Vidal-Gancedo, A. G. Kanaras, R. J. Nichols, M. Brust and D. B. Amabilino, Angew. Chem., Int. Ed., 2008, 47, 1861-1865.

25 I. Dánilá, F. Riobé, J. Puigmartí-Luis, Á. Pérez Del Pino, J. D. Wallis, D. B. Amabilino and N. Avarvari, J. Mater. Chem., 2009, 19, 44954504.

26 J. Puigmartí-Luis, E. E. Laukhina, V. N. Laukhin, Á. Pérez Del Pino, N. Mestres, J. Vidal-Gancedo, C. Rovira and D. B. Amabilino, $A d v$. Funct. Mater., 2009, 19, 934-941.

27 J. Puigmartí-Luis, Á. Pérez Del Pino, V. Laukhin, L. N. Feldborg, C. Rovira, E. Laukhina and D. B. Amabilino, J. Mater. Chem., 2010, 20, 466-474.

28 X.-J. Wang, L.-B. Xing, W.-N. Cao, X.-B. Li, B. Chen, C.-H. Tung and L.-Z. Wu, Langmuir, 2010, 27, 774-781.

29 P. J. F. Harris, Carbon Nanotubes and Related Structures, Cambridge University Press, Cambridge, 1999.

$30 \mathrm{~K}$. Tanaka, T. Yamabe and K. Fukui, The Science and Technology of Carbon Nanotubes, Elsevier, Oxford, 1999.

31 P. C. Ma, B. Z. Tang and J.-K. Kim, Carbon, 2008, 46, 1497-1505.

32 M. Á. Herranz and N. Martín, in Carbon Nanotubes and Related Structures, Wiley-VCH Verlag GmbH \& Co. KGaA, 2010, pp. 103134.

33 S. K. Samanta, A. Pal, S. Bhattacharya and C. N. R. Rao, J. Mater. Chem., 2010, 20, 6881-6890.

34 S. Srinivasan, S. S. Babu, V. K. Praveen and A. Ajayaghosh, Angew. Chem., Int. Ed., 2008, 47, 5746-5749.

35 A. Pal, B. S. Chhikara, A. Govindaraj, S. Bhattacharya and C. N. R. Rao, J. Mater. Chem., 2008, 18, 2593-2600.

36 J. Chen, C. Xue, R. Ramasubramaniam and H. Liu, Carbon, 2006, 44, 2142-2146.

37 C. Wang, Z. Wang, D. Zhang and D. Zhu, Chem. Phys. Lett., 2006, 428, 130-133.

38 D. Canevet, Á. Pérez del Pino, D. B. Amabilino and M. Sallé, J. Mater. Chem., 2011, 21, 1428-1437.

39 J. B. Torrance, B. A. Scott, B. Welber, F. B. Kaufman and P. E. Seiden, Phys. Rev. B: Condens. Matter Mater. Phys., 1979, 19, 730-741.

40 R. Bozio, I. Zanon, A. Girlando and C. Pecile, J. Chem. Phys., 1979, 71, 2282-2293.

41 V. N. Popov, Mater. Sci. Eng., R, 2004, 43, 61-102. 